\title{
Biophysical and Biochemical Markers of Red Blood Cell Fragility
}

\author{
Ariel Orbach ${ }^{a}$ Orly Zelig ${ }^{b}$ Saul Yedgar ${ }^{a}$ Gregory Barshtein ${ }^{a}$ \\ ${ }^{a}$ Department of Biochemistry, Hebrew University-Hadassah Medical School, Jerusalem, Israel; \\ b Blood Bank, Hadassah University Hospital, Jerusalem, Israel
}

\section{Keywords}

Erythrocytes - Membrane defects · RBC aging ·

RBC lesion $\cdot$ RBC storage $\cdot$ Hemolysis

\section{Summary}

Background: Red blood cells (RBCs) undergo a natural aging process occurring in the blood circulation throughout the RBC lifespan or during routine cold storage in the blood bank. The aging of RBCs is associated with the elevation of mechanical fragility (MF) or osmotic fragility (OF) of RBCs, which can lead to cell lysis. The present study was undertaken to identify RBC properties that characterize their susceptibility to destruction under osmotic/mechanical stress. Methods: RBCs were isolated from freshly donated blood or units of packed RBCs (PRBCs) and suspended in albumin-supplemented phosphate-buffered saline (PBS). In addition, PRBCs were separated by filtration through a microsphere column into two fractions: enriched with rigid (R-fraction) and deformable (D-fraction) cells. The RBCs were subjected to determination of deformability, MF and OF, moreover, the level of cell surface phosphatidylserine (PS) and the stomatin level in isolated RBC membranes were measured. Results: In the RBC population, the cells that were susceptible to mechanical and osmotic stress were characterized by low deformability and increased level of surface PS. The OF/MF was higher in the R-fraction than in the D-fraction. Stomatin was depleted in destroyed cells and in the R-fraction. Conclusion: RBC deformability, the levels of surface PS, and membrane stomatin can be used as markers of RBC fragility.

(c) 2017 S. Karger GmbH, Freiburg

\section{Introduction}

Red blood cells (RBCs) have a lifespan of about 120 days, and undergo a natural aging process occurring in the blood circulation throughout their lifespan [1].The reduction in their function occurs predominantly in the last days, and then they are removed from the bloodstream by the immune system (mainly dendritic cells). A similar aging process occurs during routine cold storage of $\mathrm{RBCs}$ in the blood bank as well, and some reports claim that it is even expedited under these conditions [2-6]. The aging-produced 'senescent' cells are characterized by the loss of cell surface area and cell morphology alterations [7], resulting from the shedding of hemoglobin $(\mathrm{Hb})$-containing vesicles $[3,6,8,9]$. The cold storage of packed RBCs (PRBCs) is associated with a continuous increase in the percentage of cells with impaired functionality [10-12]. This included increased cell rigidity (reduced deformability) and aggregability [12-14], reduced level of cell membrane stomatin [15], and translocation of phosphatidylserine (PS) to the cell surface $[9,16]$, all leading to an increased adherence to endothelial cells [14].

It follows that, together with the above parameters, senescent RBCs will be more prone to osmotic (OF) and mechanical fragility (MF). Indeed, a few studies reported that RBC aging and storage duration are associated with increased OF and MF of the cells [13, 17-21].

In the present study we hypothesized that RBCs which are susceptible to osmotic/mechanical shock are characterized by changes in their cell properties that are considered markers of blood aging and altered during RBC storage, namely the cell deformability, the level of cell surface PS, and the membrane stomatin level.

The results clearly show that the RBCs with high MF and OF are characterized by high rigidity (low deformability) and surface PS level as well as by a low level of membrane stomatin.

\section{KARGER}

() 2017 S. Karger GmbH, Freiburg 


\section{Material and Methods}

\section{Materials}

PMMA (polymethylmethacrylate) microspheres (27-32 $\mu \mathrm{m}$ diameter) were purchased from Cospheric (Santa Barbara, CA, USA) and antiaerosol pipette tip ( $1 \mathrm{ml}$ ) from Neptune Scientific (San Diego, CA, USA). Stomatin, GAPDH antibody, and the PS ligand annexin V were all obtained from Santa Cruz Biotechnology (Santa Cruz, CA, USA). Stainless-steel beads were from NationSkander California Co (Anaheim, CA, USA). NP-40 and protease inhibitor cocktail were purchased from (Sigma, St. Louis, MO, USA); Bradford assay from Bio-Rad (Rishon Le Zion, Israel)

\section{Experimental Design}

The present study employed RBCs from two sources: Freshly collected human blood samples, and PRBCs following cold storage in the blood bank (upon donor's consent according to the Hadassah Hospital Ethics Committee approval). RBC samples were taken on donation day (day 1) and following 35 days of cold storage (day 35). The cells were isolated and subjected to determination of cell deformability and fragility, cell surface phosphatidylserine (PS), and membrane stomatin level.

To further explore the relation between RBC deformability and MF/OF, $\mathrm{RBC}$ samples were subjected to separation into rigid and deformable fractions (R-fraction and D-fraction), on a column of PMMA microspheres [22]. Then each fraction was subjected to determination of RBC deformability and fragility, and membrane stomatin level.

\section{$R B C$ Storage Conditions}

Similar to our previous studies $[14,16]$, in the present study we have used non-leukoreduced PRBCs. Blood was drawn from 10 healthy donors in the Hadassah Hospital Blood Bank, following informed consent according to the Helsinki Committee Regulations Permit (98290, Hadassah Hospital, Jerusalem, Israel) and collected not-leukoreduced into standard sterile bags (Fresenius Kabi AG, Homburg, Germany), containing citrate phosphate dextrose (CPD) Immediately following collection, RBCs were isolated by centrifugation (Roto Silenta 630RS, Tuttlingen, Germany) for $6 \mathrm{~min}\left(2,367 \mathrm{rpm}, 24^{\circ} \mathrm{C}\right)$ followed by removal of the plasma. Units of concentrated non-leukodepleted RBCs were stored in citrate phosphate dextrose adenine (CPDA-1) under the standard conditions $\left(2-6{ }^{\circ} \mathrm{C}\right.$ for 5 weeks) at the Hadassah Hospital Blood Bank.

\section{Isolation of $R B C s$}

\section{Preparation of RBC Samples from Freshly Collected Blood}

RBCs from blood samples collected from healthy donors were isolated from plasma by centrifugation $(500 \times g$ for $10 \mathrm{~min})$, washed (three times) from plasma by centrifugation in phosphate-buffered saline (PBS; pH 7.4), and suspended in PBS at $10 \%$ hematocrit.

\section{Preparation of RBC Samples from Stored PRBCs}

From 10 PRBC units, $5 \mathrm{ml}$ were drawn, washed twice by centrifugation $(500$ $\times g$ for $10 \mathrm{~min}$ ) in PBS, and suspended in PBS at $10 \%$ hematocrit.

\section{RBC Fractionation into Rigid and Deformable Cells}

In a previous study, we have shown that the percentage of rigid RBCs in PRBC units increases with storage duration $[13,14]$. Accordingly, in this experiment, to obtain significant fractions of rigid cells, PRBCs stored for 35 days were separated into fractions of rigid (R-fraction) and deformable cells (D-fraction), by fractionation on column of PMMA microspheres (PMPMS), using a modification of the method of Deplaine et al. [22]: A total of $1 \mathrm{~g}$ of dry PMPMS were suspended in $6 \mathrm{ml}$ PBS supplemented with 1\% albumin (PBS-A). $600 \mu \mathrm{l}$ of the bead suspension was poured into an inverted $1 \mathrm{ml}$ antiaerosol pipette tip and allowed to settle, leading to the formation of a bead layer above the filter. A total of $600 \mu \mathrm{l}$ of RBC suspension ( $2 \%$ hematocrit) was placed on the PMPMS layer.

The PMPMS layer was then washed with $8 \mathrm{ml}$ of PBS-A. The downstream sample, containing the D-fraction, was collected, and the RBC layer retained in the PMPMS, containing the R-fraction, was separated from the PMPMS by centrifugation $(300 \times g$ for $10 \mathrm{~min})$ and washed twice in PBS.

\section{Determination of RBC Hemolysis (\% Hemolysis)}

$\mathrm{The} \mathrm{Hb}$ concentration in the supernatant was determined by its optical density at $540 \mathrm{~nm}$. The hemolysis level at each mechanical or osmotic stress was expressed as \% of the total lysis, according to the formula:

$\%$ hemolysis $=100 \times\left(\mathrm{OD}_{\mathrm{S}}-\mathrm{OD}_{0}\right) /\left(\mathrm{OD}_{\mathrm{T}}-\mathrm{OD}_{0}\right)$

where $\mathrm{OD}_{0}=\mathrm{OD}$ of supernatant obtained from the control, untreated RBCs, $\mathrm{OD}_{\mathrm{S}}=\mathrm{OD}$ of supernatant obtained from RBC subjected to MS/OS, $\mathrm{OD}_{\mathrm{T}}$ $=\mathrm{OD}$ of supernatant from RBC subjected to total hemolysis.

For total cell lysis, equal amounts of RBCs were incubated for $10 \mathrm{~min}$ in distilled water [13], and centrifuged (at $14,000 \times g$ for $10 \mathrm{~min}$ ) to remove the cell debris.

\section{Determination of $M F / O S$}

\section{Mechanical Stress}

Mechanical stress was induced using the conventional method previously described [13]. In brief: $3 \mathrm{ml}$ of RBC suspension were rocked (at 40 cycles $/ \mathrm{min}$ ) for $1 \mathrm{~h}$ at room temperature in glass test tubes $(13 \times 100 \mathrm{~mm})$, containing 5 steel beads $(3.175 \mathrm{~mm})$

\section{Osmotic Stress}

Osmotic stress was applied using the common method, as previously described [13]: In brief: $10 \mu \mathrm{l}$ of RBCs were suspended in $1 \mathrm{ml} \mathrm{NaCl}$ solution at increasing concentrations $(0,3.0,3.5,4.0,4.5,5.0,6.0,7.0,8.0,9.0 \mathrm{~g} / \mathrm{l})$. The cells were then centrifuged at $500 \times g$ for $10 \mathrm{~min}$ at room temperature; the supernatant was collected and subjected to $\mathrm{Hb}$ determination as above.

The mechanical fragility index (MFI), was expressed as a percent of the total hemolysis. The osmotic fragility index (OSI), was defined by the concentration of $\mathrm{NaCl}$ that exerted $50 \%$ hemolysis.

\section{Isolation of the Cells Surviving the MS/OS}

Subsequent to application of MS or OS, the remaining intact cells were isolated by centrifugation, washed twice in PBS $(500 \times g$ for $10 \mathrm{~min})$ and suspended at $10 \%$ hematocrit in isotonic PBS for determination of deformability, surface PS, and membrane stomatin. The level of hemolysis following treatments does not exceed 5.0\%.

\section{Determination of RBC Deformability}

The present research employed the computerized Cell Flow-Properties Analyzer (CFA), designed and constructed in our laboratory [13, 14]. RBC deformability was determined by monitoring the elongation of RBCs, while adherent to a slide, under flow-induced shear stress $[13,14]$. In brief, $50 \mu \mathrm{l}$ of RBC suspension ( $1 \%$ hematocrit, in PBS supplemented by $0.5 \%$ of albumin) are inserted into the flow chamber (adjusted to $200 \mu \mathrm{m}$ gap) which contains an uncoated polystyrene slide. The adherent RBCs are then subjected to controllable flow-induced shear stress, and their deformability is determined by the change in cell shape, as expressed by the axial ratio (elongation ratio): $E R=a / b$, with $\mathrm{a} / \mathrm{b}=$ the major/the minor cell axes. $\mathrm{ER}=1$ reflects a round $\mathrm{RBC}$, undeformed at the applied shear stress. The CFA image analysis program measures the ER for each individual cell, and provides the deformability distribution (ER-Dis) in a large RBC population (at least 3,500 \pm 300 cells) as a function of shear stress $[13,14]$. The accuracy of the axes measurement is about $10 \%$. Therefore, RBCs with $\mathrm{ER} \leq 1.1$ are defined as 'undeformable' cells (UDFC), namely the cells that do not deform under high shear stress (3.0 Pa in the present study). As shown 
and discussed in our previous studies, when considering the potential of RBCs with low deformability to induce microvascular occlusion, the portion of undeformable cells is more clinically relevant than the shift in average values.

\section{Determination of Stomatin Level in RBC Membranes}

To examine the relation of the membrane stomatin level to the cell fragility, we determined the average RBC stomatin content and its change induced by MS and OS. To this end, RBC suspension was subjected to lysis (less than 5\% of hemolysis, see above) by OS or MS, followed by mild centrifugation ( $5 \mathrm{~min}$ at $500 \times g$ ) to precipitate the intact cells. The membrane-containing supernatant was collected and subjected to membrane isolation by centrifugation (10 $\mathrm{min}$ at $14,000 \times g$ ), and determination of membrane stomatin level. Concomitantly, the same amount of control, untreated RBCs (no MS/OS) were subjected to complete hemolysis, membrane isolation, and stomatin determination.

For stomatin determination, membrane proteins were extracted by dissolving the membranes in $1 \% \mathrm{NP}-40$, containing protease inhibitor cocktail, while immersion in ice for $10 \mathrm{~min}$ (with frequent mixing), and the protein concentration was measured by Bradford assay. $20 \mu \mathrm{g}$ of the protein extract were subjected to determination of stomatin level using direct enzyme-linked immunosorbent assay (ELISA) with stomatin antibody. The lysates were incubated in parallel with GAPDH for normalization of protein content.

\section{Determination of PS at RBC Surface}

RBC surface PS was determined by the binding of the PS-specific ligand, fluorescein 5-isothiocyanate(FITC)-labeled human annexin V. The ligand (8 $\mathrm{nmol} / \mathrm{l}$ ) was incubated with RBCs (suspended in $200 \mu \mathrm{l}$ HEPES-buffered saline at $0.016 \%$ hematocrit) for $20 \mathrm{~min}$ at $37^{\circ} \mathrm{C}$ in the dark. To remove unbound annexin $\mathrm{V}$, the RBCs were washed and suspended in $500 \mu \mathrm{l}$ of the same buffer, and their fluorescence was measured in a fluorescence-activated cell sorter (FACS) to determine the number of PS-positive RBCs. Data acquisitions were performed on a Becton Dickinson FACScan (Becton Dickinson, San Jose, CA, USA), and analysis was done with CellQuest software (Becton Dickinson). A total of 10,000 events were acquired for each sample. The percentage of annexin $\mathrm{V}$-FITC-positive erythrocytes was determined from the fluorescence signal in excess of that obtained with a negative (unlabeled) control RBC sample.

\section{Statistical Analysis}

Data, analyzed and tested for statistical significance using the paired Student test, is presented as mean \pm SD. Statistical difference, analyzed with the SPSS 21 software package (SPSS Inc. Chicago, IL, USA), was considered significant at $\mathrm{p}<0.05$.

\section{Results}

\section{Osmotic and Mechanical Stress Destroyed Primarily RBCs with Low Deformability}

To examine the susceptibility of rigid RBCs to stress, we analyzed the change in the distribution of RBC deformability (ER-Dis) exerted by MS or OS. Figure 1 shows that the ER-Dis for the RBC populations that survived the OS/MS-induced hemolysis shifted towards higher deformability (higher ER values), implying that the RBCs which were lysed by the MS/OS were the rigid cells. This is further supported by the results presented in table 1 showing that the percent of undeformable RBCs (\% UDFC, having ER $\leq 1.1$ ) decreased markedly after application of MS/OS.

In addition, as demonstrated by figure 2, strong correlation $(\mathrm{r}=0.92 ; \mathrm{p}<0.0002)$ between the \% of UDFC and the MFI has been observed.

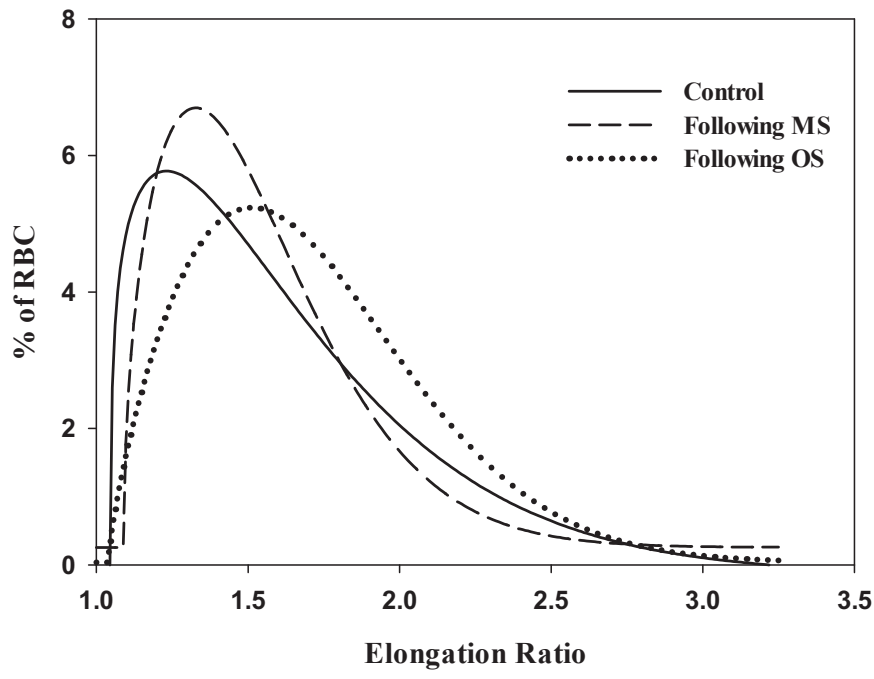

Fig. 1. The right shift of ER distribution of stored RBCs remaining after application of mechanical ( $2.8 \%$ hemolysis) or osmotic ( $4.7 \%$ hemolysis) stress.

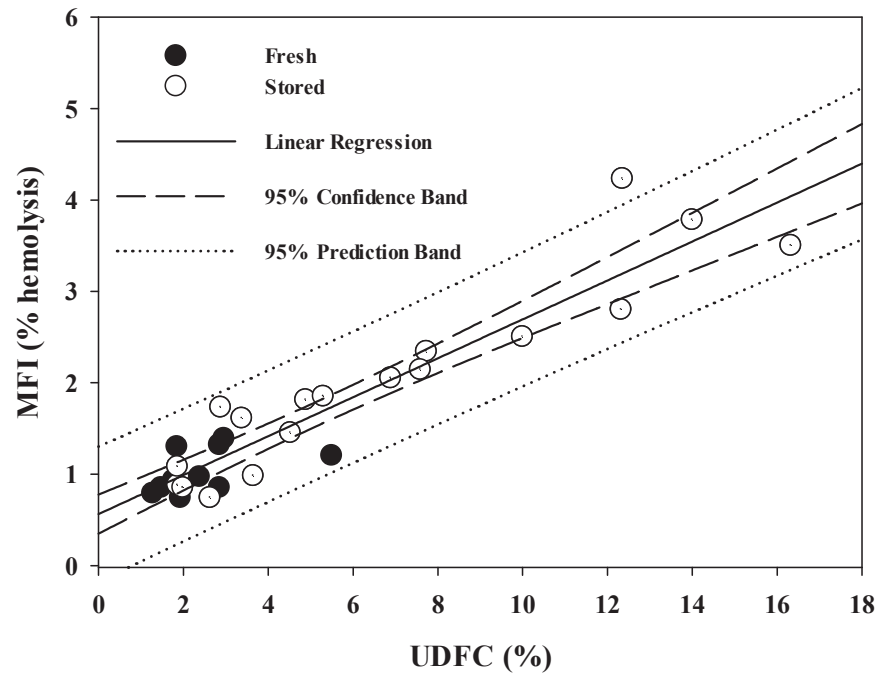

Fig. 2. RBC MFI versus \% of undeformable cells (UDFC) for freshly donated or stored RBCs.

Table 1. The population of RBCs that survived osmotic/mechanical stress are characterized by depletion of undeformable cells (UDFC, ER $\leq 1.1)^{\mathrm{a}}$

\begin{tabular}{llll}
\hline Treatment & $\%$ UDFC & \multirow{2}{*}{$\begin{array}{l}\text { p value } \\
\text { (pair test) }\end{array}$} \\
\cline { 2 - 3 } & before stress & after stress & \\
\hline Osmotic stress & $5.18 \pm 4.44$ & $2.35 \pm 0.95$ & 0.001 \\
Mechanical stress & $5.18 \pm 4.44$ & $3.12 \pm 1.39$ & 0.005 \\
\hline${ }^{\text {a Each datum is the mean } \pm \text { SD for } 10 \text { samples of PRBCs. }}$ \\
\hline
\end{tabular}

The susceptibility of rigid RBCs to MS and OS is further demonstrated by the fractionation of the RBCs into rigid and deformable cell fractions (R-fraction and D-fraction, see 'Material and Methods'). Table 2 shows that the fragility indices (expressing susceptibility to stress) for the fractions of rigid cells (R-fraction) was markedly higher than for the deformable cells (D-fraction). 
Table 2. Rigid RBCs exhibit high fragility and low stomatin level ${ }^{\mathrm{a}}$

\begin{tabular}{lccl}
\hline Parameter & D-fraction & R-fraction & $\begin{array}{l}\text { p value } \\
\text { (pair test) }\end{array}$ \\
\hline MFI & $1.13 \pm 0.39$ & $3.15 \pm 0.29$ & 0.003 \\
OFI & $0.59 \pm 0.19$ & $0.68 \pm 0.13$ & 0.002 \\
Relative stomatin & 1.0 & $0.805 \pm 0.037$ & 0.03 \\
$\quad$ concentration & & \\
\hline $\begin{array}{l}\text { R-fraction = Rigid RBC-enriched fraction, obtained by separation on a micro- } \\
\text { bead column; D-fraction = deformable RBC-enriched fraction, remaining } \\
\text { after separation of R-fraction. }\end{array}$ & \\
\hline
\end{tabular}

Table 3. RBCs that are destroyed under osmotic/mechanical stress exhibit low level of membrane stomatin.

\begin{tabular}{|c|c|c|c|}
\hline \multirow[t]{2}{*}{ Treatment } & \multicolumn{2}{|c|}{ Relative stomatin concentration, $\%$} & \multirow[t]{2}{*}{$\mathrm{p}$ value } \\
\hline & $\begin{array}{l}\text { RBCs before } \\
\text { treatment }\end{array}$ & destroyed RBCs & \\
\hline Osmotic stress & 100 & $72.00 \pm 15.36$ & 0.0205 \\
\hline Mechanical stress & 100 & $76.97 \pm 18.89$ & 0.0179 \\
\hline
\end{tabular}

\section{Rigid RBCs Are Characterized by Translocation of PS to the Cell Surface}

PS is normally located in the inner leaflet of the RBC membrane, but under abnormal conditions, especially storage [16], that are associated with changes in cell mechanical properties [13] PS is translocated to the cell surface. The cells that exhibit surface PS were identified by the binding of the PS-specific ligand annexin V [16]. Figure 3, depicting the percent of undeformable RBCs (\% UDFC) versus the percent of annexin V-labeled RBCs (expressing surface PS), shows a strong correlation $(\mathrm{r}=0.915 ; \mathrm{p}=0002)$ between $\mathrm{RBC}$ rigidity and surface PS. Figure 4 shows that the \% of PS-expressing (annexin Vlabelled) RBCs decreased by the application of MS ( $p=0.0021)$.

\section{Osmotic or Mechanical Stress Destroyed Predominantly Cells with Low Levels of Membrane Stomatin}

Table 3, depicts the stomatin level in the fraction of cells that were lysed by MS/OS relatively to the average in untreated RBCs ( $=100 \%$, see 'Material and Methods' for details). The table shows that the fragile RBCs are characterized by a low level (72-77\%) of membrane stomatin.

In addition, the results presented in table 2 show that the stomatin level in the fraction of rigid RBCs (R-fraction) is lower than in the fraction of deformable cells ( $D$-fraction).

\section{Discussion}

The aging of RBCs, occurring during their lifespan in the blood (in vivo) or during storage in the blood bank (in vitro), is characterized by the formation of microdefects in the $\mathrm{RBC}$ membrane

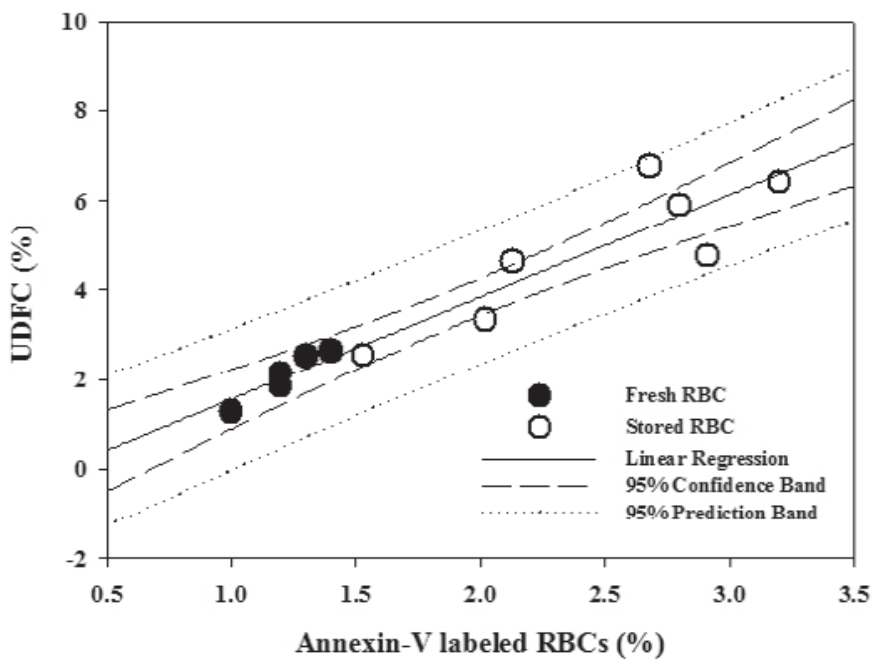

Fig. 3. The $\%$ of undeformable cells (UDFC) in the RBC population versus percent of cells labelled with the PS ligand annexin-V.

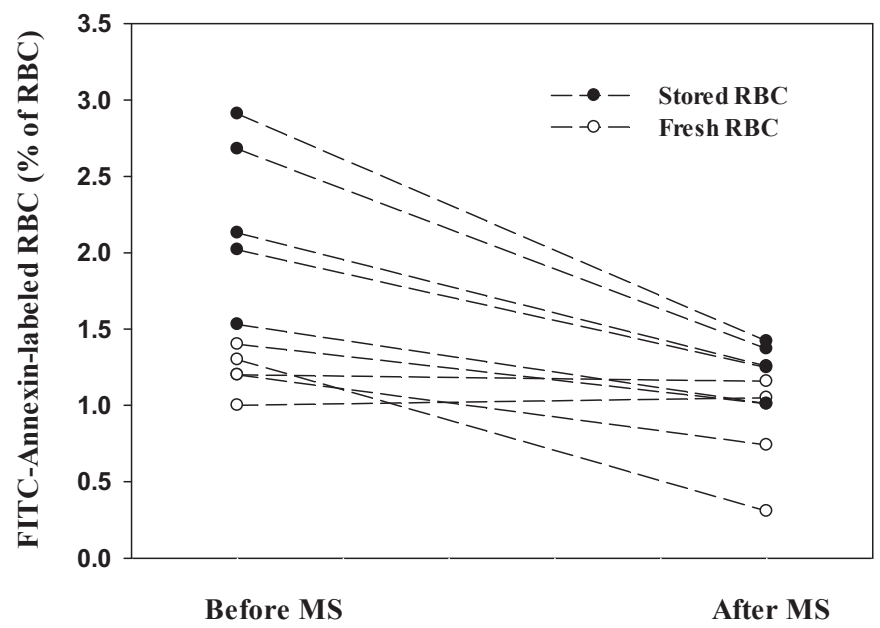

Fig. 4. MS-induced decrease in the percentage of RBCs labelled with the PS ligand annexin-V.

[23-25]. The topological defects, studied by atomic force microscopy [23-25], appear normally as domains with grain-like structures ('grains') of up to $200 \mathrm{~nm}$, which later merge to form large defects of 400-1,000 nm [24]. The formation of microdefects makes the cell susceptible to stress [24].

When RBCs are subjected to shear stress, the cell membrane deforms until the membrane reaches its 'yield point'. Beyond this threshold point, additional stress results in irreversible plastic deformation of the membrane, which accelerates with accumulation of microdefects in the membrane, leading to the cell destruction $[26,27]$. Thus, this suggests that senescent (aged) RBCs will be destroyed under a relatively low level of mechanical stress.

A similar conclusion was presented by other groups. Sakota et al. [28] and Yokoyama et al. [29] studied RBC hemolysis during blood pumping (using rotary pump) and have speculated that the RBC hemolysis exerted by this procedure is due to selective destruction of aged, fragile cells under pumping-induced mechanical stress $[28,29]$.

In the present study, we demonstrated that the cells that were destroyed under low mechanical stress are characterized by low de- 
formability, high level of surface PS, and reduced level of membrane stomatin.

Previous studies have linked reorganization of the RBC membrane $[4,7,30]$, expressed particularly by changes in RBC deformability [31], PS translocation [16] and membrane stomatin level [3], to cell aging. In the present study, we show that these measures express the RBC susceptibility to mechanical stress, as expressed by the cell mechanical fragility.

In addition, the present study shows that RBCs with low deformability and stomatin level are markedly more susceptible to osmotic stress. This can be explained by the fact that the ratio of the cell surface area-to-volume, a key determinant of RBC rigidity [32] and osmotic fragility [33], decreases subsequent to the shedding of stomatin-containing membrane vesicles [9-11].

In conclusion, the present study shows that RBCs that are destroyed by mechanical/osmotic stress are characterized by low de- formability and membrane stomatin level, and high level of surface PS, thereby suggesting that these cell properties, in addition to being markers of RBC aging, are measures of MF and OF.

\section{Acknowledgments}

This study was supported by a grant from the Hebrew University, Jerusalem, Israel (to S. Yedgar), and the Israel Science Foundation (to G. Barshtein; 1661/13). We thank Ms. Olga Fredman (The Hebrew University, Faculty of Medicine) and Hanna Greenbaum (Blood Bank, Hadassah University Hospital) for their technical assistance.

\section{Disclosure Statement}

The authors declare no conflict of interests.

\section{References}

1 Willekens FL, Roerdinkholder-Stoelwinder B Groenen-Dopp YA, Bos HJ, Bosman GJ, van den Bos AG, Verkleij AJ, Werre JM: Hemoglobin loss from erythrocytes in vivo results from spleen-facilitated vesiculation. Blood 2003;101:747-751.

2 Dinkla S, Peppelman M, Van Der Raadt J, Atsma F, Novotny VM, Van Kraaij MG, Joosten I, Bosman GJ Phosphatidylserine exposure on stored red blood cells as a parameter for donor-dependent variation in product quality. Blood Transfus 2014;12:204-209.

3 Salzer U, Zhu R, Luten M, Isobe H, Pastushenko V, Perkmann T, Hinterdorfer P, Bosman GJ: Vesicles generated during storage of red cells are rich in the lipid raft marker stomatin. Transfusion 2008;48:451-462.

4 D'Alessandro A, Kriebardis AG, Rinalducci S, Antonelou MH, Hansen KC, Papassideri IS, Zolla L: An update on red blood cell storage lesions, as gleaned through biochemistry and omics technologies. Transfusion 2014:55:205-219.

5 Tzounakas VL, Kriebardis AG, Georgatzakou HT, Foudoulaki-Paparizos LE, Dzieciatkowska M, Wither MJ, Nemkov T, Hansen KC, Papassideri IS, D'Alessandro A, Antonelou MH: Glucose 6-phosphate dehydrogenase deficient subjects may be better 'storers' than donors of red blood cells. Free Radic Biol Med 2016;96:152-165.

6 D'Alessandro A, D’Amici GM, Vaglio S, Zolla L: Timecourse investigation of SAGM-stored leukocyte-filtered red bood cell concentrates: from metabolism to proteomics. Haematologica 2012;97:107-115.

7 Blasi B, D'Alessandro A, Ramundo N, Zolla L: Red blood cell storage and cell morphology. Transfus Med 2012;22:90-96.

8 Malka R, Delgado FF, Manalis SR, Higgins JM: In vivo volume and hemoglobin dynamics of human red blood cells. PLoS Comput Biol 2014;10:e1003839.

9 Bosman GJ, Lasonder E, Groenen-Dopp YA, Willekens FL, Werre JM, Novotny VM: Comparative proteomics of erythrocyte aging in vivo and in vitro. J Proteomics 2010;73:396-402.

10 Bosman GJ: Survival of red blood cells after transfusion: PROCESSES and consequences. Front Physiol 2013;4:376.

11 Bosman GJ, Werre JM, Willekens FL, Novotny VM: Erythrocyte ageing in vivo and in vitro: structural aspects and implications for transfusion. Transfus Med 2008;18:335-347.
12 Tuo WW, Wang D, Liang WJ, Huang YX: How cell number and cellular properties of blood-banked red blood cells of different cell ages decline during storage. Plos One 2014;9

13 Barshtein G, Gural A, Manny N, Zelig O, Yedgar S, Arbell $\mathrm{D}$ : Storage-induced damage to red blood cell mechanical properties can be only partially reversed by rejuvenation. Transfusion Med Hemother 2014;41: 197-204.

14 Relevy H, Koshkaryev A, Manny N, Yedgar S, Barshtein G: Blood banking-induced alteration of red blood cell flow properties. Transfusion 2008;48:136-146.

15 Kriebardis AG, Antonelou MH, Stamoulis KE, Economou-Petersen E, Margaritis LH, Papassideri IS: Storage-dependent remodeling of the red blood cell membrane is associated with increased immunoglobulin $g$ binding, lipid raft rearrangement, and caspase activation. Transfusion 2007;47:1212-1220.

16 Koshkaryev A, Zelig O, Manny N, Yedgar S, Barshtein G: Rejuvenation treatment of stored red blood cells reverses storage-induced adhesion to vascular endothelial cells. Transfusion 2009;49:2136-2143.

17 Malachi T, Bogin E, Gafter U, Levi J: Parathyroid hormone effect on the fragility of human young and old red blood cells in uremia. Nephron 1986;42:52-57.

18 Jikuya T, Tsutsui T, Shigeta O, Sankai Y, Mitsui T: Species differences in erythrocyte mechanical fragility: comparison of human, bovine, and ovine cells. Asaio J 1998;44:M452-455.

19 Raval JS, Waters JH, Seltsam A, Scharberg EA, Richter E, Kameneva MV, Yazer MH: Menopausal status affects the susceptibility of stored RBCs to mechanical stress. Vox Sang 2011;100:418-421.

20 Tarasev M, Alfano K, Chakraborty S, Zubair A: Evaluation of novel in-vitro RBC fragility metrics as ageindependent measures of stored RBC quality. Transfusion 2011;51(suppl):79A.

21 Tarasev M, Chakraborty S, Alfano K: RBC mechanical fragility as a direct blood quality metric to supplement storage time. Mil Med 2015;180:150-157.

22 Deplaine G, Safeukui I, Jeddi F, Lacoste F, Brousse V, Perrot S, Biligui S, Guillotte M, Guitton C, Dokmak S, Aussilhou B, Sauvanet A, Cazals Hatem D, Paye F, Thellier M, Mazier D, Milon G, Mohandas N, Mercereau-Puijalon O, David PH, Buffet PA: The sensing of poorly deformable red blood cells by the human spleen can be mimicked in vitro. Blood 2011;117:e88-95.
23 Girasole M, Pompeo G, Cricenti A, Longo G, Boumis G, Bellelli A, Amiconi S: The how, when, and why of the aging signals appearing on the human erythrocyte membrane: an atomic force microscopy study of surface roughness. Nanomedicine 2012;6:760-768.

24 Kozlova E, Chernysh A, Moroz V, Sergunova V, Gudkova O, Kuzovlev A: Nanodefects of membranes cause destruction of packed red blood cells during long-term storage. Exp Cell Res 2015;337:192-201.

25 Pompeo G, Girasole M, Cricenti A, Boumis G, Bellelli A, Amiconi S: Erythrocyte death in vitro induced by starvation in the absence of $\mathrm{Ca}(2+)$. Biochim Biophys Acta 2012;1798:1047-1055.

26 Negri C, Sellerio AL, Zapperi S, Miguel MC: Deformation and failure of curved colloidal crystal shells. Proc Natl Acad Sci U S A 2015;112:14545-14550.

27 Guz AN, Dyshel' MS, Nazarenko VM: Fracture and stability of materials and structural members with cracks: Approaches and results. Int Appl Mech 2004, 40:1323-1359.

28 Sakota D, Sakamoto R, Sobajima H, Yokoyama N, Waguri S, Ohuchi K, Takatani S: Mechanical damage of red blood cells by rotary blood pumps: selective destruction of aged red blood cells and subhemolytic trauma. Artif Organs 2008;32:785-791.

29 Yokoyama N, Sakota D, Nagaoka E, Takatani S: Alterations in red blood cell volume and hemoglobin concentration, viscoelastic properties, and mechanical fragility caused by continuous flow pumping in calves. Artif Organs 2011;35:791-799.

30 Tzounakas VL, Georgatzakou HT, Kriebardis AG, Voulgaridou AI, Stamoulis KE, Foudoulaki-Paparizos LE, Antonelou MH, Papassideri IS: Donor variation effect on red blood cell storage lesion: A multivariable, yet consistent, story. Transfusion 2016;56:1274-1286.

31 Bosch FH, Werre JM, Schipper L, RoerdinkholderStoelwinder B, Huls T, Willekens FL, Wichers G, Halie MR: Determinants of red blood cell deformability in relation to cell age. Eur J Haematol 1994;52:35-41.

32 Mohandas N, Clark MR, Jacobs MS, Shohet SB: Analysis of factors regulating erythrocyte deformability. J Clin Invest 1980;66:563-573.

33 van der Vegt SG, Ruben AM, Werre JM, de Gier J, Staal GE: Membrane characteristics and osmotic fragility of red cells, fractionated with anglehead centrifugation and counterflow centrifugation. Br J Haematol 1985;61:405-413. 